\title{
Stereochemical effects in the EI mass spectra of cis- and trans-fused octa/hexahydro-3,l-benzoxazines and -benzothiazines
}

\author{
Pentti Oksman, ${ }^{1 \mathrm{a}}$ Péter Csomós, ${ }^{2}$ Ferenc Fülöp, ${ }^{2}$ Vladimir Ovcharenko, ${ }^{1}$ Henri Kivelä, ${ }^{1}$ \\ and Kalevi Pihlaja ${ }^{{ }^{*}}$ \\ ${ }^{1}$ Department of Chemistry, University of Turku, FIN-20014 Turku, Finland \\ ${ }^{2}$ Institute of Pharmaceutical Chemistry, University of Szeged, H-6701 Szeged, POB 121, \\ Hungary \\ E-mail: kpihlaja@utu.fi
}

\section{Dedicated to Professor Nikolai Zefirov on the occasion of his $70^{\text {th }}$ birthday (received 05 Oct 04; accepted 20 Dec 04; published on the web 01 Jan 05)}

\begin{abstract}
The electron ionization mass spectra of cis- and trans-fused 2-oxo- (1,2), and 2-thioxo-4phenyloctahydro-2H-3,1-benzoxazines (3,4), 2,4-diphenylhexahydro-3,1-benzoxazines (5,6) and 2-phenylimino-4-phenylhexahydro-3,l-benzoxazines $\mathbf{( 7 , 8 )}$ and -benzothiazines $\mathbf{( 9 , 1 0 )}$ were recorded, and the fragmentation pathways established and compared to their 4-unsubstituted counterparts. Effects of stereochemistry, substitution, and (in the case of 2-phenylimino derivatives) of an intramolecular cyclization of the $[\mathrm{M}-\mathrm{H}]^{+}$ions were observed in the mass spectra. In general, mass spectral behavior was similar for the isomeric compounds although they could usually be differentiated from each other based on the relative abundances of their characteristic fragment ions.
\end{abstract}

Keywords: Electron ionization, stereochemical effects, hexahydro-3,l-benzoxazines, intramolecular cyclization, substituent effects

\section{Introduction}

Saturated benzoxazines and -thiazines form a class of heterocyclic compounds which possess remarkable pharmaceutical activity. ${ }^{1}$ They are also interesting from an organic synthesis and structural chemistry point of view.

As a continuation of our systematic mass spectrometric studies on 1,3- and 3,1octahydrobenz-oxazines and related thiazines $^{2-8}$ the mass spectrometric behavior of cis- / transfused isomeric pairs shown in Scheme 1 is now studied. 

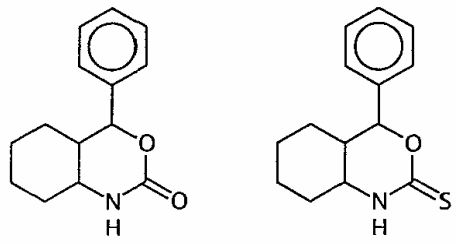

$M^{+*}=231$

1 trans

2 cis

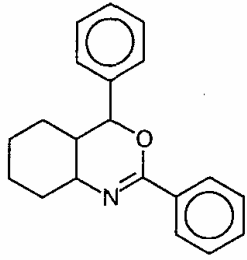

$M^{+*}=291$

5 trans

6 cis

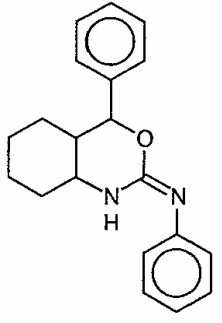

$M^{+*}=306$

7 trans

8 cis

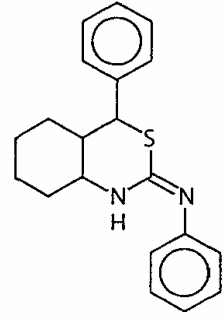

$\mathrm{M}^{+*}=322$

9 trans

10 cis

Scheme 1. The compounds studied.

It has been shown earlier ${ }^{5}$ that in the case of 2-thioxoperhydro-3,l-benzoxazines, cis- and trans-fused isomers gave similar spectra, although the cis-type compounds fragmented more easily. The isomers could, however, be distinguished from each other. The gas phase enolisa-tion or thioenolisation was not found which probably also reflects the lack of ring-chain tautomerism. This was also true for octahydro-3,1-benzoxazines ${ }^{6}$ with a heteroaryl moiety at position 2 . It was shown previously ${ }^{7}$ that an intramolecular cyclization could occur between the ring nitrogen atom and the ortho-carbon of the phenylimino moiety at position 2 which was always accompanied ${ }^{8}$ with a hydrogen loss from position 1 .

The aim of this study was to find out whether the phenyl substitution at position 4 has any significant effect on the mass-spectral fragmentations and whether any cyclization occurs between an ortho- carbon of the phenylimino group and the ring nitrogen. It was also interesting to see how much the higher polarizability of sulfur as compared with that of oxygen atom alters the fragmentations. The possibility to differentiate cis- and trans-fused isomers based on their low-resolution mass spectra was also a question of interest.

\section{Experimental Section}

Synthesis. The synthetic pathways to the aliphatic cyclocondensed 1,3-oxazines and -thiazines studied are shown in Schemes 2 and 3. The syntheses of all compounds were described earlier ${ }^{9}$ except for thiazines $\mathbf{9}$ and 10. The reactions of $\mathbf{A}$ and $\mathbf{B}$ with ethyl chloroformate followed with sodium methoxide gave 2-oxo-octahydro-2 $\mathrm{H}$-3,1-benzoxazines $\mathbf{1}$ and $\mathbf{2}$ in good yields. The corresponding 2-thiones $\mathbf{3}$ and $\mathbf{4}$ were prepared by reacting $\mathbf{A}$ or $\mathbf{B}$ with carbon disulfide. The cyclizations of $\mathbf{A}$ and $\mathbf{B}$ with ethyl benzimidate resulted in 2,4-diphenyl-4a,5,6,7,8,8a-hexahydro4H-3,1-benzoxazines $\mathbf{5}$ and $\mathbf{6}$ and the treatment of $\mathbf{A}$ and $\mathbf{B}$ with phenyl isothiocyanate provided the thiourea derivatives 11 and 12, which were treated with methyl iodide and alkali to give 2phenylimino-3,l-benzoxazines $\mathbf{7}$ and $\mathbf{8}$ with retention of configuration of the 4-phenyl substituent. $^{9}$

When thioureas 11 and 12 were refluxed in ethanol containing dry HC1, thiazines $\mathbf{9}$ and 10 were obtained in good yields. In the ring closure it is possible to have either retention or inversion of configuration. According to NMR-measurements, both $\mathbf{9}$ and $\mathbf{1 0}$ attain inverted configurations. 
$\left(4 R^{*}, 4 a R^{*}, 8 \mathrm{a} R^{*}\right)-4-P h e n y l-2(1 H)$-phenylimino-4a,5,6,7,8,8a-hexahydro-4H-3,1-benzothiazine (9). Thiourea derivative 11 (0.50 g, $1.47 \mathrm{mmol})$ was dissolved in ethanol (10 $\mathrm{mL})$ containing $22 \%$ of dry $\mathrm{HCl}$. The reaction mixture was refluxed for $2 \mathrm{~h}$. After evaporation the residue was dissolved in water $(5 \mathrm{ml})$ and the solution neutralized with potassium carbonate and extracted with dichloromethane $(3 \times 5 \mathrm{ml})$. After drying $\left(\mathrm{Na}_{2} \mathrm{SO}_{4}\right)$ and evaporation of the organic phase the residue was recrystallised from diisopropyl ether - ethyl acetate (ca. 9:1) providing 9 as white crystals in $72 \%$ yield, m.p. $225-228{ }^{\circ} \mathrm{C} .{ }^{1} \mathrm{H}$ NMR $\left(\mathrm{CDCl}_{3}\right)$ : 7.31-7.20 (m, 7H, H-arom.), 7.06-6.95 (m, 3H, H-arom.), 4.04 (d, 1H, H4, $J=10.7 \mathrm{~Hz}$ ), 3.20 (td, 1H, H8a, $J=2 \times 10$ and 4 Hz), 1.98 (m, 1H, H8eq), 1.88 (br quartet, 1H, H4a, $J=3 \times 10 \mathrm{~Hz}$ ), 1.78 (br d, 1H, H7eq, $J=13$ Hz), 1.67 (br d, 1H, H6eq, $J=13 \mathrm{~Hz}$ ), 1.52-1.42 (m, 2H, H5eq and H8ax), 1.34 (m, 1H, H7ax), 1.20 (m, 1H, H6ax), 0.82 (m, 1H, H5ax). ${ }^{13} \mathrm{C}$ NMR $\left(\mathrm{CDCl}_{3}\right)$ : 138.7 (very br), 128.7-128.8 (two overlapping peaks), 128.5, 128.1, 122.8, 122.2 (br), 57.7 (br, C8a), 51.9 (C4), 44.5 (br, C4a), 34.4 (br, C8), 28.8 (C5), 25.7 (C6), 24.5 (br, C7).

\section{$\left(4 R^{*}, 4 a R^{*}, 8 \mathrm{a} S^{*}\right)-4-P h e n y l-2(1 H)$-phenylimino-4a,5,6,7,8,8a-hexahydro-4H-3,l-benzo-}

thiazine (10). This compound was prepared according to the above procedure from 12 in $83 \%$ yield, m.p. $245-247{ }^{\circ} \mathrm{C} .{ }^{1} \mathrm{H}$ NMR (CDCl 3 + drop TFA): 11.3, 10.9 (exchangeable protons), 10.3 (br s, 1H, H1), 7.42-7.33 (m, 6H, H-arom.), 7.30-7.28 (m, 4H, H-arom.), 4.57 (d, 1H, H4, J = 9.2 Hz), 3.90 (m, 1H, H8a), 2.48 (m, 1H, H4a), 1.93 (m, 1H, H8x), 1.85-1.76 (m, 2H, H8y and H7x),

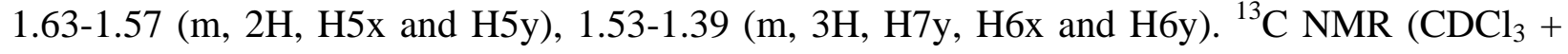
drop TFA): 166.8 (1C, C2), 135.9 (br, 1C), 134.0 (1C), 129.7 (s, 2C), 129.5 (s, 2C), 129.4 (1C), 129.0 (1C), 128.2 (s, 2C), 126.7 (s, 2C), 51.9 (br, 1C, C8a), 46.6 (br, 1C, C4), 37.9 (1C, C4a), 29.8 (1C, C8), 26.5 (1C, C5), 22.9 (br, 1C, C7), 20.8 (br, 1C, C6).

Purity of the compounds was checked with ${ }^{1} \mathrm{H}$ NMR. The samples were fairly stable at room temperatures but some of them decomposed after a relatively small rise of temperature (e.g. in the ion source).

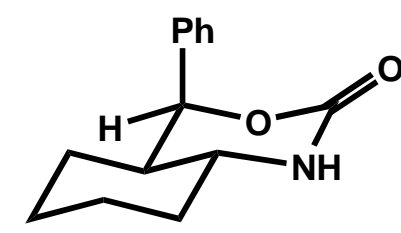

1

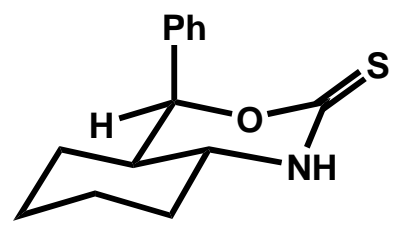

3
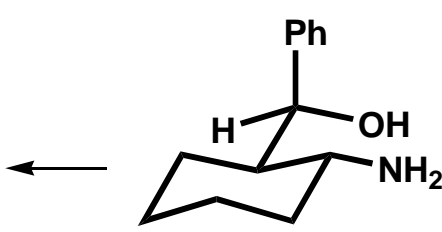

A

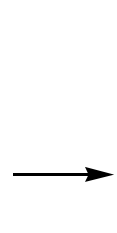

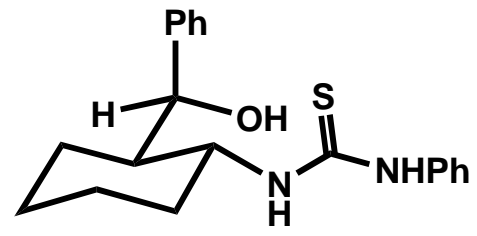

11

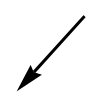

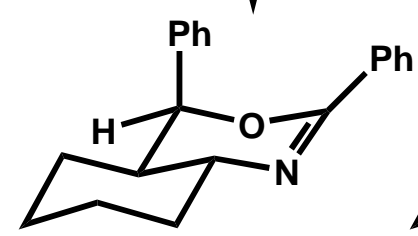

5

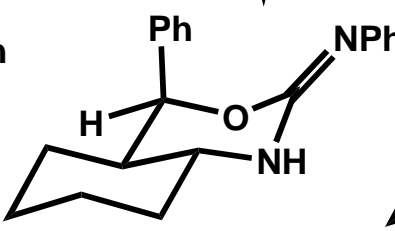

7

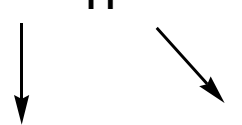

Scheme 2 


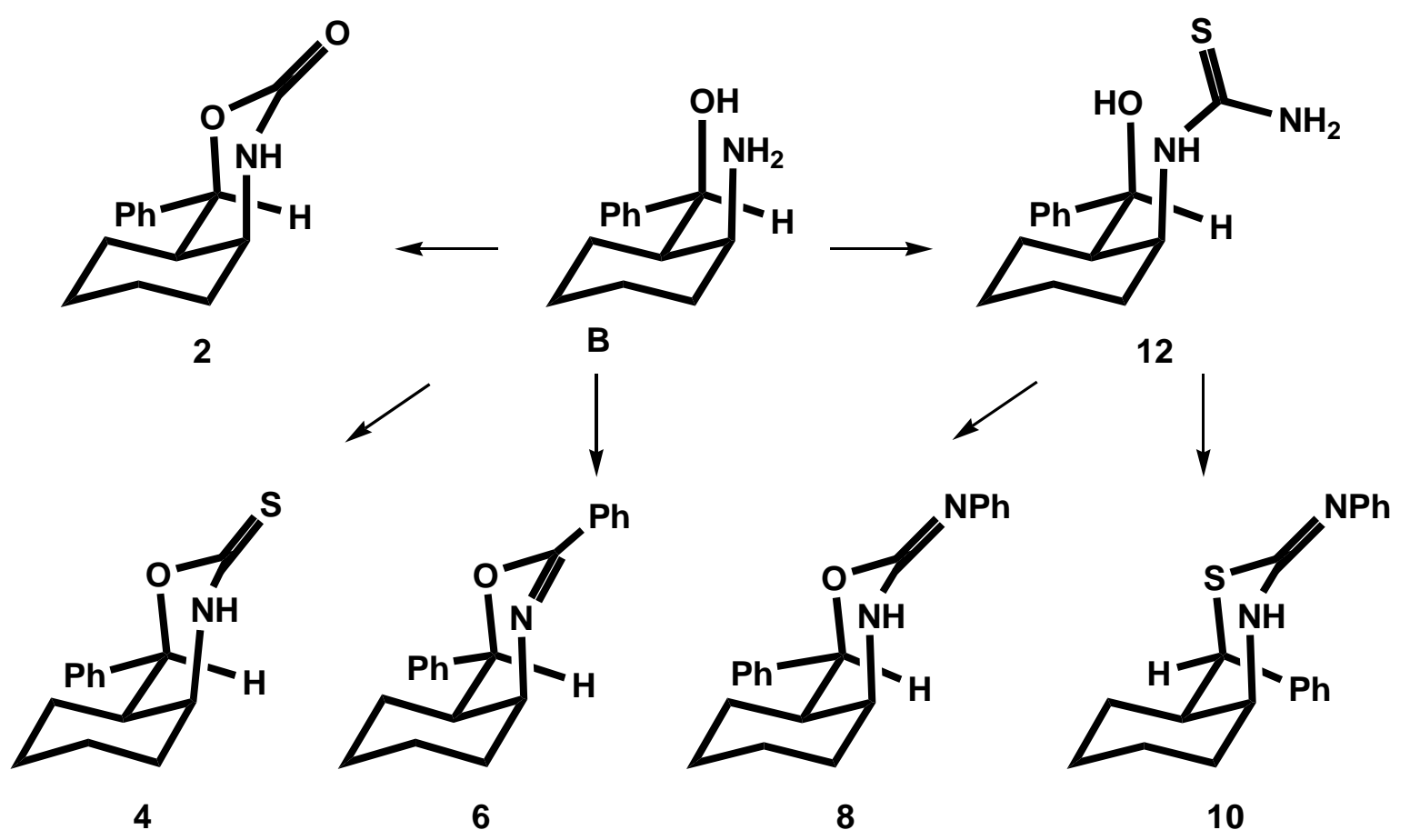

\section{Scheme 3}

Mass spectrometry. The low resolution $(\mathrm{R}=1000) \mathrm{EI}^{+}$mass spectra were recorded on a VG7070E double-focussing mass spectrometer (VG Analytical, UK) equipped with an OPUS data system. Samples were introduced into spectrometer using water-cooled direct insertion probe at ambient temperatures. The ionization energy of $70 \mathrm{eV}$, trap current of $100 \mu \mathrm{A}$, source temperature of $180^{\circ} \mathrm{C}$ and acceleration voltage of $6 \mathrm{kV}$ were used.

High resolution spectra $(\mathrm{R}=8000)$ were obtained on a ZABSpec-oaTOF instrument (Fisons Instruments, UK). This instrument was also used for linked scan and MS/MS measurements. The source conditions were $70 \mathrm{eV} / 200 \mu \mathrm{A} / 160^{\circ} \mathrm{C}$. The acceleration voltage was $8 \mathrm{kV}$. The collision energy in oaTOF chamber was $800 \mathrm{eV}$. The residual air was acting as the collision gas. In linked scan measurements, He was used as the CID target gas for the high energy (8 keV) collisions. The transmission of $30 \%$ was used. The accurate masses were obtained using peak matching with PFK as the reference compound. All the high-resolution measurements for the ions discussed in the text were within 5 ppm from the calculated values.

NMR spectroscopy. The NMR spectra of compounds $\mathbf{9}$ and $\mathbf{1 0}$ were recorded on a Bruker Avance $500 \mathrm{NMR}$ spectrometer $\left(500.13 \mathrm{MHz}\right.$ for ${ }^{1} \mathrm{H}$ and $125.76 \mathrm{MHz}$ for ${ }^{13} \mathrm{C}$ ) in $\mathrm{CDCl}_{3}$ using TMS as an internal reference. The spectra were measured at $25{ }^{\circ} \mathrm{C}$ both with and without adding a drop of trifluoroacetic acid (TFA); for 10, ${ }^{1} \mathrm{H}$ spectrum without TFA was recorded also at $55{ }^{\circ} \mathrm{C}$. The experiments consisted of standard ${ }^{1} \mathrm{H}$ and ${ }^{13} \mathrm{C}\left\{{ }^{1} \mathrm{H}\right\}$ NMR, 1D gs-NOESY or NOEdifference, dqf-COSY, ${ }^{1} \mathrm{H}\left\{{ }^{13} \mathrm{C}\right\}$-HSQC and ${ }^{1} \mathrm{H}\left\{{ }^{13} \mathrm{C}\right\}$-HMBC, using vendor-supplied pulse programs. 


\section{Results and Discussion}

The structures of compounds 1-8 have been verified earlier. ${ }^{9}$ Compound 9 displayed large vicinal diaxial couplings between protons $\mathrm{H} 4$ and $\mathrm{H} 4 \mathrm{a}$, and between H4a and H8a (10.7 and ca. $10 \mathrm{~Hz}$, respectively), thus confirming both the trans-fusion and the axial position of $\mathrm{H} 4$ for this compound. Consistently with this, presaturation of the $\mathrm{H} 4$ resonance resulted in an NOE enhancement of protons $\mathrm{H} 5 \mathrm{ax}$ and H8a. ${ }^{1} \mathrm{H}$ and ${ }^{13} \mathrm{C}$ signals were broadened at $25{ }^{\circ} \mathrm{C}$ to the point that some ${ }^{13} \mathrm{C}$ signals could not be observed, indicating the presence of dynamic processes (e.g. endo-exo-tautomerism of the double bond or E-Z-isomerism with respect to it). Addition of a drop of TFA resulted in sharper NMR lines with all carbon signals being visible. Compound $\mathbf{1 0}$ was only slightly soluble in $\mathrm{CDCl}_{3}$ at $25^{\circ} \mathrm{C}$ showing very broad ${ }^{1} \mathrm{H}$ resonances. At $55{ }^{\circ} \mathrm{C}$, signals were sharper, though still broadened. Again, adding TFA increased the signal resolution, and dramatically improved as well the solubility, allowing measurements at $25{ }^{\circ} \mathrm{C}$. In these conditions, 10 showed a large coupling $(9.2 \mathrm{~Hz})$ between $\mathrm{H} 4$ and $\mathrm{H} 4 \mathrm{a}$, indicating their mutual trans orientation, and thus also the predominance of $\mathrm{N}$-out conformation (i.e. a conformation where N1 is equatorial w.r.t. the cyclohexane moiety). 1D NOESY confirmed that in the predominant ring-invertomer $\mathrm{H} 4$ is facing the cyclohexane ring (e.g. an NOE in H8ax due to H4 was observed). At $55{ }^{\circ} \mathrm{C}$ without the presence of TFA, the coupling between $\mathrm{H} 4$ and $\mathrm{H} 4 \mathrm{a}$ was resolved in the $\mathrm{H} 4$ signal; $J(\mathrm{H} 4, \mathrm{H} 4 \mathrm{a})=6.6 \mathrm{~Hz}$. Assuming this coupling has a value of $10.7 \mathrm{~Hz}$ in the limiting $\mathrm{N}$-out conformer (axial-axial relationship, cf. 9) and $2.5 \mathrm{~Hz}$ in the $\mathrm{N}$-in conformer (equatorial-equatorial relationship as shown in Scheme 3), we conclude that $\mathbf{1 0}$ exists in these conditions as a roughly 50:50 mixture of these conformers. A further indication for the fact that indeed the $\mathrm{Ph}$ is axial in compounds $\mathbf{3}, \mathbf{5}$, and $\mathbf{7}$ is their C-8a chemical shift which is around 50 ppm whereas for $\mathbf{1 0}$ it is ca. $58 \mathrm{ppm}$ - so one can see the shielding effect of axial $\mathrm{Ph}$ in the former. To further prove this situation we remeasured the H4,H4a couplings for compounds 3 $(5.0 \mathrm{~Hz})$ and $5(5.3 \mathrm{~Hz})$ which are what one can expect from an eq,ax-type coupling between these protons.

The 70-eV EI mass spectra of compounds 1-10 are listed in Table 1 which shows that all compounds except 2-oxo-derivatives $\mathbf{1}$ and $\mathbf{2}$ exhibit intense molecular ion peaks under the EI conditions. The $\mathrm{M}^{+\bullet}$ peaks are especially abundant for sulphur-containing derivatives $\mathbf{3 , 4 , 9}$ and $\mathbf{1 0}$ and give rise to the base peaks in thiazines $\mathbf{9}$ and $\mathbf{1 0}$. Note that $[\mathrm{M}-\mathrm{H}]^{+}$ions were detected only in the spectra of 2-phenylimino-substituted compounds (7-10). An abundant loss of hydrogen occurred from their molecular ions $\left([\mathrm{M}-\mathrm{H}]^{+}\right.$ions, $\left.40-90 \% \mathrm{RA}\right)$. This loss is most probably due to the intramolecular cyclization between the ortho-carbon of the iminophenyl group and the ring nitrogen (Scheme 4) - a phenomenon often observed in oxazines, thiazines and pyrimidinones with e.g. a benzyl or 2-phenylimino substituent in a position next to the ring nitrogen atom. ${ }^{7}$ However, elimination of one of the bridgehead or benzylic hydrogen atoms is also likely. The possible hydrogen migration between 1-NH and 2-NPh moieties can further stabilize the structure thus formed.

Some similarities exist between the fragmentations of 2-phenylimino oxazines and corresponding thiazines. However, due to the greater ability of sulfur to maintain the charge some of the main fragmentation routes are different. The fragment ions appear to be less abundant and more numerous in the thiazine spectra. The differences between the LR spectra of 
cis- and trans-fused isomers are very small in thiazines but in case of oxazines the isomers can be differentiated based on their LR spectra.

The main difference between the fragmentation routes of 2-phenylimino-oxazines (7 and 8) and -thiazines (9 and 10) is that the $\mathrm{M}^{+\bullet}$ of oxazines do not release hydroxyl radicals although $\mathrm{SH}^{\bullet}$ is released from the $\mathrm{M}^{+\bullet}$ of thiazines. Also, the ion $\mathrm{C}_{13} \mathrm{H}_{16} \mathrm{~N}^{+}$at $m / z 186$, which in oxazines is formed directly from $\mathrm{M}^{+\bullet}$, can be obtained from the $\mathrm{M}^{+\bullet}$ of thiazines only after the loss of $\mathrm{SH}^{\bullet}$. Also, the ions $\mathrm{C}_{7} \mathrm{H}_{5} \mathrm{NS}^{+\bullet}(\mathrm{m} / \mathrm{z} 135)$ are observed in the CID spectrum of $\mathrm{M}^{+\bullet}$ of thiazines, although there is no counterpart $\mathrm{C}_{7} \mathrm{H}_{5} \mathrm{NO}^{+\bullet}$ ions in the CID spectra of oxazines. This reflects the role of the sulfur atom which localizes the charge in the phenyliso-thiocyanate ions.

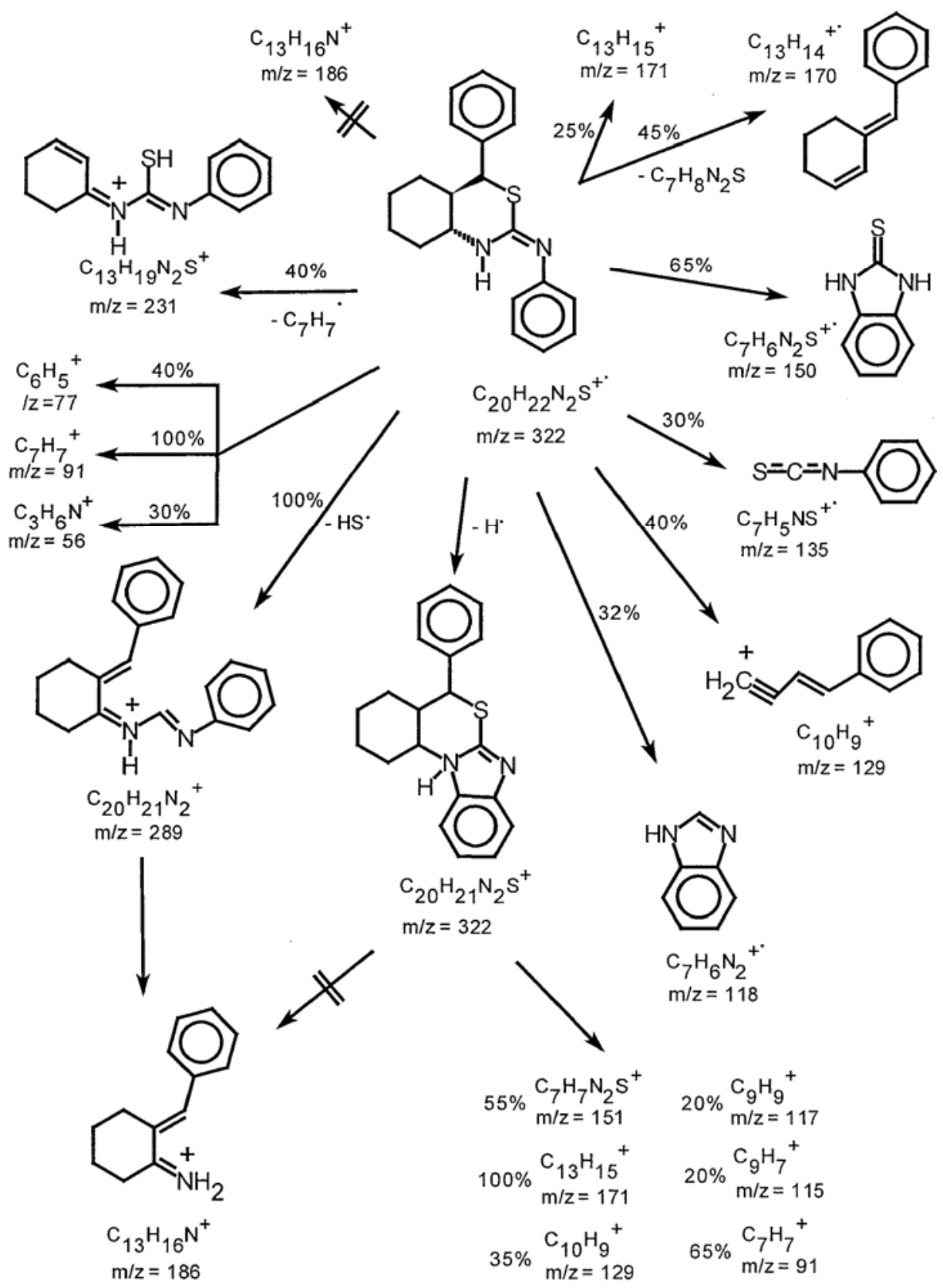

Scheme 4 
Major differences can also be found between the CID-oaTOF spectra of $\mathrm{M}^{+\bullet}$ ions of cis- and trans-fused isomers of these compounds. While the trans-fused isomers $7(X=O)$ and $9(X=S)$ give abundant cyclic $\mathrm{C}_{7} \mathrm{H}_{6} \mathrm{~N}_{2} \mathrm{X}^{+\bullet}$ ions (100\% and 65\% RA, respectively), the base peak in the CID spectrum of cis-fused 2-phenylimino-oxazine $\mathbf{8}$ corresponds to the protonated phenylurea, $\mathrm{C}_{7} \mathrm{H}_{9} \mathrm{~N}_{2} \mathrm{O}^{+}$( $\mathrm{m} / \mathrm{z}$ 137), which is formed through loss of $\mathrm{C}_{13} \mathrm{H}_{13}{ }^{\bullet}$ from $\mathrm{M}^{+} \bullet$. The cis-fused 2phenylimino-thiazine $\mathbf{1 0}$ loses $\mathrm{SH}^{\bullet}$ radical but very little of the (supposedly cyclic) ion $\mathrm{C}_{7} \mathrm{H}_{6} \mathrm{~N}_{2} \mathrm{~S}^{+\bullet}$. Furthermore, the loss of hydrogen from $\mathrm{M}^{+\bullet}$ results in almost identical $[\mathrm{M}-\mathrm{H}]^{+}$ions for the cis- and trans-fused isomers in both pairs of compounds. This agrees well with the $[\mathrm{M}-\mathrm{H}]^{+}$cyclization hypothesis, but can also be due to a hydrogen rearrangement.

The behaviour of the 2-phenyl compounds 5 and $\mathbf{6}$ resembles that of the 2-oxo and 2-thioxo compounds. The ring-fusion isomers are easily differentiated on the basis of their EI spectra since the ions at $\mathrm{m} / \mathrm{z} 200$ and $\mathrm{m} / \mathrm{z} 186$ for the trans form 5 are much more abundant than for the cis form 6 (Scheme 6). Additional stereospecific fragmentations were revealed by their CIDoaTOF-spectra. Thus, the main fragmentation route of the cis form leads to the ions $\mathrm{C}_{13} \mathrm{H}_{14}{ }^{\bullet}(\mathrm{m} / \mathrm{z}$ 170), but the trans form gives the ions $\mathrm{C}_{13} \mathrm{H}_{14} \mathrm{NO}^{+}(\mathrm{m} / \mathrm{z} 200)$ instead. Although the oaTOF-CID spectra of $\mathrm{M}^{+\bullet}$ for the cis- and trans-fused isomers are different, the loss of hydrogen makes the CID spectra of their $[\mathrm{M}-\mathrm{H}]^{+}$ions quite similar. Stereochemical effects of ring annelation on the relative abundance of $[\mathrm{M}-\mathrm{H}]^{+}$ions have been described in the literature, ${ }^{10}$ but in this case the fragments and abundances of the high intensity ions are practically the same for both the cis- and trans-fused isomers, and only the relative abundances of some low intensity ions are different.

Thus, the CID spectra of compounds 7-10 show stereospecific fragmentation patterns unless the stereoisomers produce a common structure (in the case of $[\mathrm{M}-\mathrm{H}]^{+}$ions).

The EI spectra of the 2-oxo isomers 1 and $\mathbf{2}$ show that they fragmented primarily via the loss of $\mathrm{CO}_{2}$ from the $\mathrm{M}^{+}$ions (Scheme 5). They differed more clearly from each other than the corresponding thioxo-isomers $\mathbf{3}$ and $\mathbf{4}$. For instance, the $\mathrm{M}^{+\bullet}$ ions are less stable, and the [M$\left.\mathrm{CO}_{2}\right]^{+\bullet}$ ions more abundant in the spectrum of the trans-fused $\mathbf{1}$ than in that of $\mathbf{2}$. 

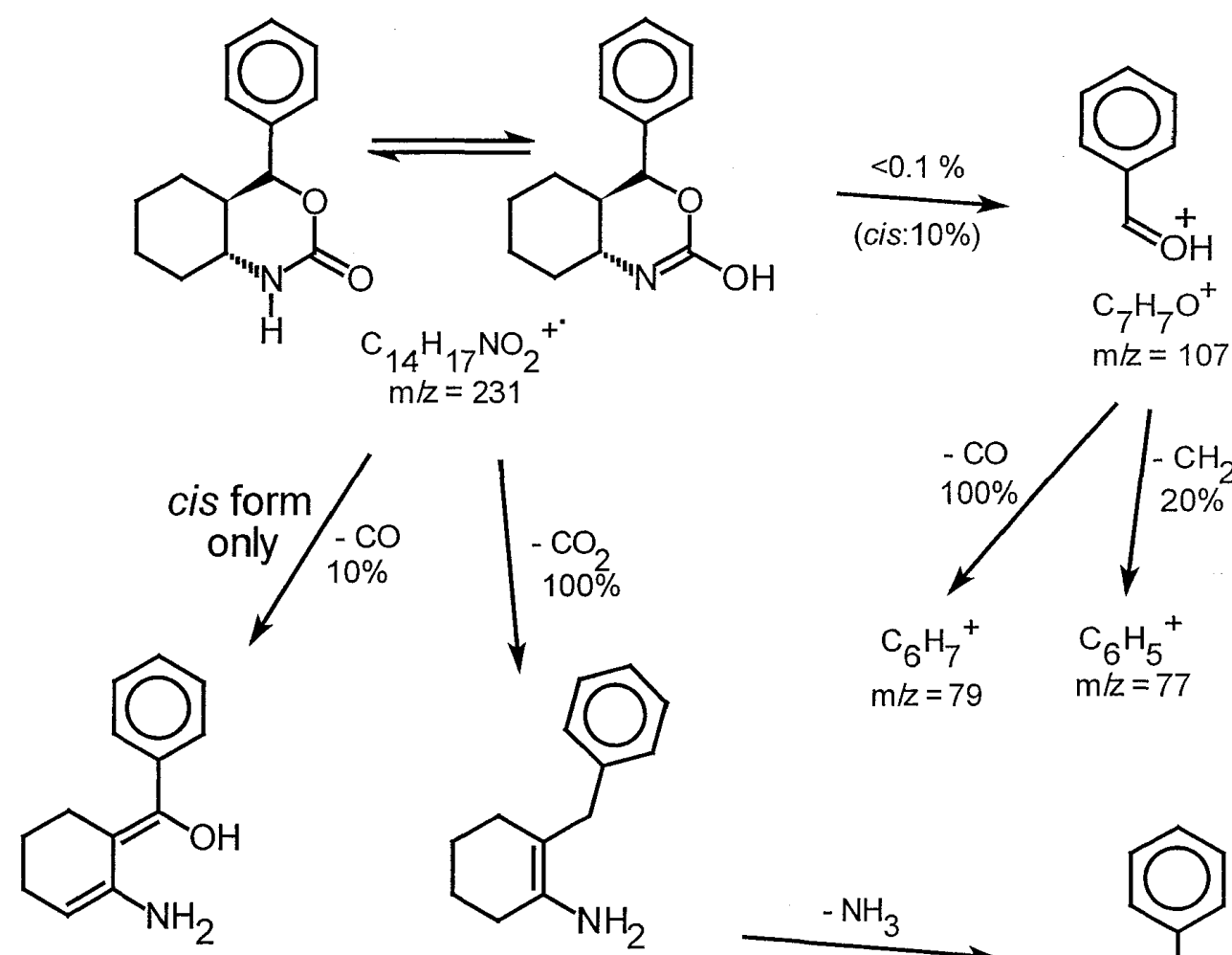

$\mathrm{C}_{13} \mathrm{H}_{17} \mathrm{NO}^{+*}$

$\mathrm{m} / \mathrm{z}=203$
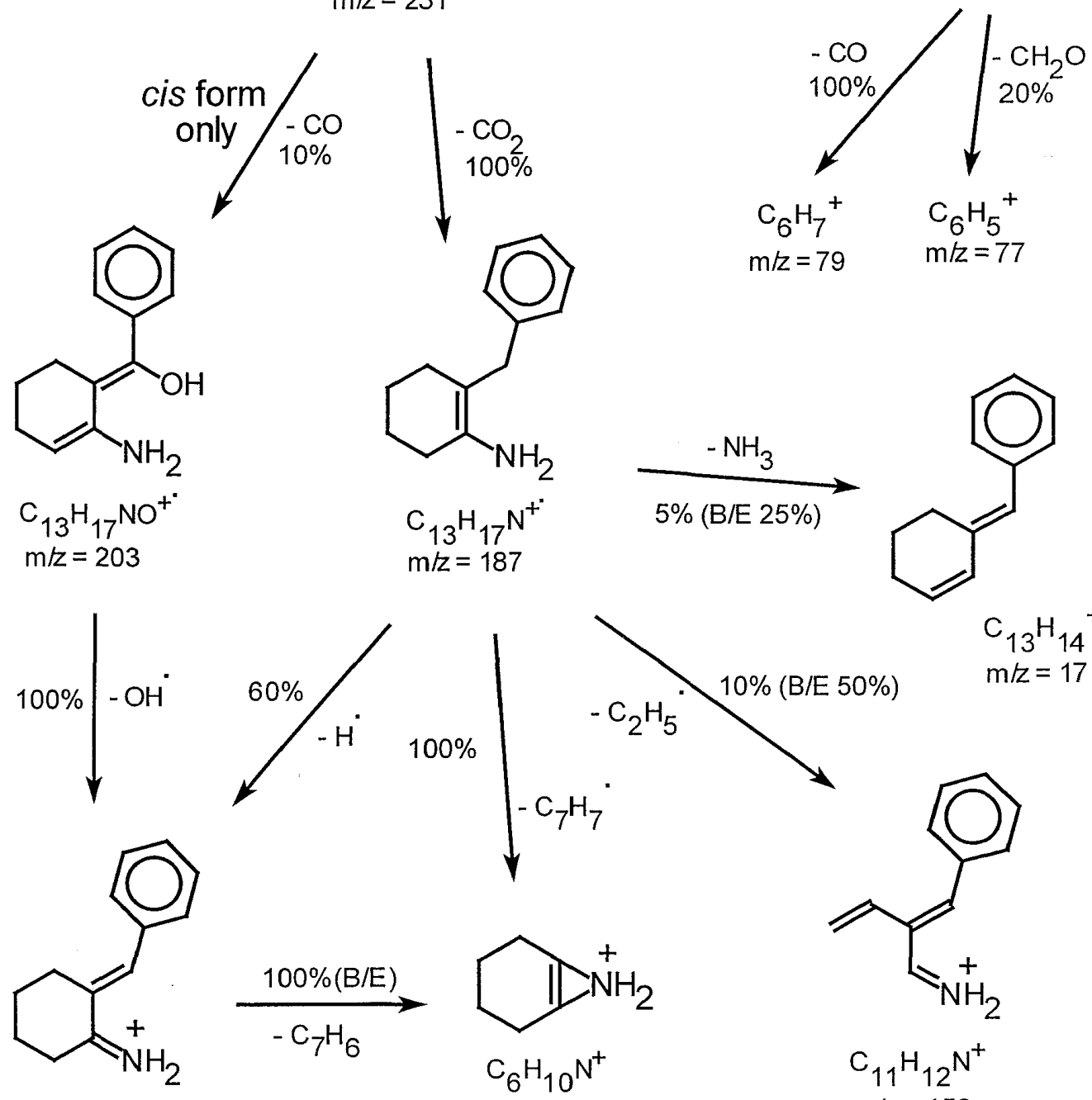

$\mathrm{C}_{6} \mathrm{H}_{7}^{+}$

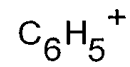

$\mathrm{m} / \mathrm{z}=79 \quad \mathrm{~m} / \mathrm{z}=77$

$\mathrm{C}_{13} \mathrm{H}_{16} \mathrm{~N}^{+}$

$\mathrm{m} / \mathrm{z}=96$

$$
\begin{aligned}
& \mathrm{C}_{13} \mathrm{H}_{14}{ }^{+} \\
& \mathrm{m} / \mathrm{z}=17
\end{aligned}
$$

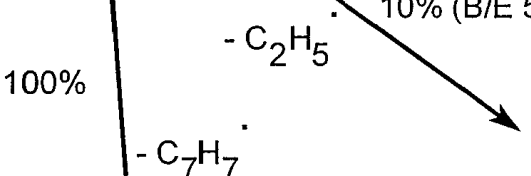

$\mathrm{m} / \mathrm{z}=186$

\section{Scheme 5}

However, the EI spectra of cis and trans-fused isomers of 2-thioxo compounds $\mathbf{3}$ and $\mathbf{4}$ also provided a few peaks with sufficiently different abundancies which allowed their differentiation. Fragmentations of compounds $\mathbf{3}$ and $\mathbf{4}$ proceeded mainly by the losses of $\mathrm{HS}^{\bullet}, \mathrm{COS}^{\bullet}$, and $\mathrm{C}_{7} \mathrm{H}_{7}{ }^{\bullet}$ from the $\mathrm{M}^{+\bullet}$, similarly to earlier findings. ${ }^{4,5}$ 


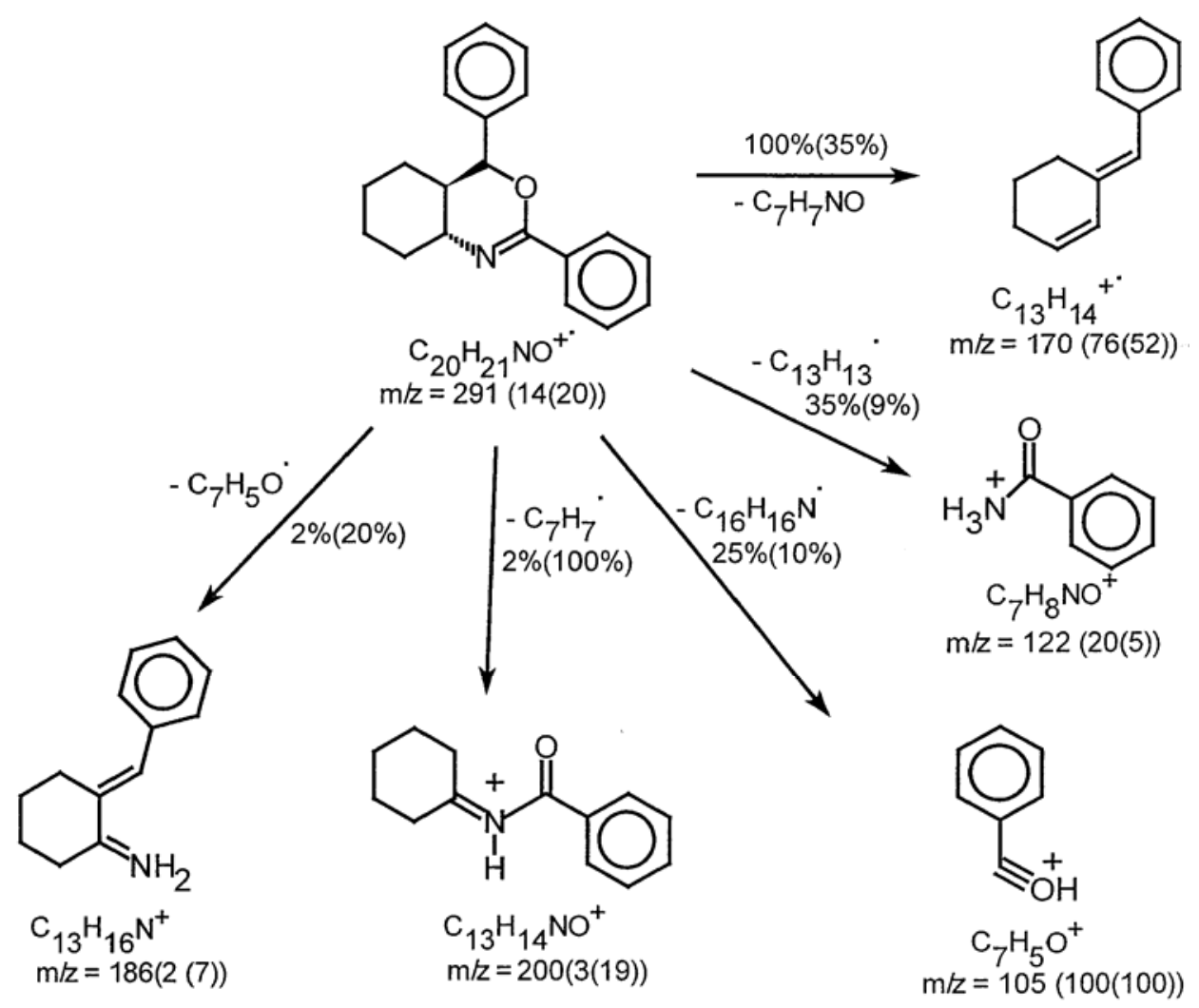

\section{Scheme 6}

\section{Conclusions}

It was demonstrated for the 2-phenylimino substituted compounds that under EI conditions a hydrogen loss from their molecular ions is followed by cyclization to the ring nitrogen atom. This observation is in a good agreement with earlier results.

In general, the mass spectral behavior is similar for the isomeric compounds studied. The EI spectra of the isomeric 2-phenylimino thiazines are almost identical but the daughter-ion spectra of their molecular ions are different. The corresponding oxazines differ mainly by the higher stability of the molecular ion of the trans isomer as compared with that of the cis isomer, probably because the latter forms a protonated phenylurea ion more easily. The isomeric 2phenyl oxazines produce similar EI mass spectra except that the loss of benzyl radical, $\mathrm{C}_{7} \mathrm{H}_{7}{ }^{\bullet}$, from the molecular ion is the main pathway only for the cis isomer but not for the trans isomer. The spectra of the isomeric 2-thioxo compounds exhibit only fairly small differences but those of the 2-oxo-compounds are clearly different.

The stabilities of the thioxo-compounds under electron ionization do not practically differ from those of the 4-unsubstituted homologues, probably because the sulfur atom better stabilizes the ions due to charge localization. In contrast, the difference between the isomeric oxo- 
compounds is much clearer. So, the 2-oxo-compounds studied are clearly less stable under electron ionization than their 4-unsubstituted homologues.

\section{References}

1. Kleeman, A.; Engel, J. Pharmaceutical Substances, Thieme, Stuttgart, 1999.

2. Vainiotalo, P.; Partanen, T.; Fülöp, F.; Bernáth, G.; Pihlaja, K. J. Am. Soc. Mass Spectrom. 1991, 2, 125.

3. Pihlaja, K.; Liukko-Sipi, S.; Fülöp, F.; Bernáth, G.; Vainiotalo, P. Rapid Commun. Mass Spectrom. 1991, 5, 230.

4. Partanen, T.; Vainiotalo, P.; Stájer, G.; Bernáth, G.; Pihlaja, K. Org. Mass Spectrom. 1990, 25, 615.

5. Vainiotalo, P.; Fülöp, F.; Stájer, G.; Bernáth, G.; Pihlaja, K. Acta Chem. Scand. 1990, 44, 165.

6. Vainiotalo, P.; Forró, E.; Fülöp, F. ACH-Models Chem. 1998, 135, 653.

7. Oksman, P.; Pihlaja, K.; Fülöp, F.; Bernáth, G. Rapid Commun. Mass Spectrom. 1995, 9, 615.

8. Pihlaja, K.; Lötjönen, L.; Fülöp, F.; Bernáth, G.; Vainiotalo, P. Rapid Commun. Mass Spectrom. 1990, 4, 279.

9. Csomós, P.; Bernáth, G.; Sohár, P.; Csámpai, A.; De Kimpe, N.; Fülöp, F. Tetrahedron 2001, 57, 3175.

10. Turecek, F. In Applications of Mass Spectrometry to Organic Stereochemistry, Splitter, J.S.; Turecek, F., Eds; VCH, 1994; pp 265-298. 